\title{
Perbandingan Respon Struktur Kapal Oil Chemical Tanker di North Atlantic Dan Indonesian Waterways
}

\author{
Dimas Romansah ${ }^{\left.1{ }^{*}\right)}$, Ahmad Fauzan Zakki ${ }^{1)}$, Imam Pujo Mulyatno ${ }^{1)}$ \\ Topan Firmandha ${ }^{2)}$, Sukron Makmun ${ }^{21}$ \\ ${ }^{1)}$ Departemen Teknik Perkapalan, Fakultas Teknik, Universitas Diponegoro \\ Jl. Prof. Soedarto, SH, Kampus Undip Tembalang, Semarang, Indonesia 50275 \\ ${ }^{2)}$ Biro Klasifikasi Indonesia \\ Jl. Yos Sudarso No. 38-40, Tanjung Priok, DKI Jakarta 14320
}

\begin{abstract}
Abstrak
Perhitungan kekuatan konstruksi sangat diperlukan dalam mendesain sebuah kapal. Desain tersebut tidak lepas juga dari regulasi yang digunakan dalam perhitungan. Dalam hal ini, dilakukan analisa perbandingan desain konstruksi kapal yang diberikan 2 pembebanan, yang pertama pembebanan untuk kondisi perairan North Atlantic Ocean, yang kedua pembebanan pada kondisi perairan Indonesian Waterways . Perhitungan pembebanan struktur menggunakan regulasi BKI. Diketahui, regulasi BKI tersebut mempunyai rujukan kondisi lingkungan di daerah Samudera Atlantik Utara $\left(H_{w}\right.$ untuk nilai $\left.C_{0}\right)$. BKI seharusnya mempunyai regulasi desain konstruksi yang disesuaikan dengan kondisi perairan Indonesia, dimana untuk nilai dari $C_{0}$ dan $H_{w}$ lebih kecil. Harapanya dengan hasil ini , perancangan konstruksi dapat lebih efektif dan tidak mubazir. Kapal yang diteliti adalah kapal oil chemical tanker type 3. Analisa menggunakan software MSC Patran. Diketahui hasil respon struktur kapal pada perairan North Atlantic Ocean pada kondisi air tenang adalah 19,1 Mpa, sagging 23,9 Mpa dan hogging 59,1 Mpa. Kemudian pada perairan Indonesian Waterways pada kondisi air tenang adalah 19,1 Mpa, sagging 12 Mpa, dan hogging 48,4 Mpa. Selisih respon struktur adalah 0\%, 49,79\% dan 18,10\%. Untuk rekomendasi desain, perhitungan nilai modulus profil dan tebal plat yang dapat direduksi tidak boleh lebih dari 27,33\%.
\end{abstract}

Copyright (C) 2017, KAPAL, 1829-8370 (p), 2301-9069(e)

Kata Kunci : Oil Chemical Tanker, North Atlantic Ocean, Indonesian Waterways

\section{PENDAHULAN}

Indonesia merupakan negara kepulauan terbesar di dunia, terletak pada $6^{\circ} \mathrm{LU}-11^{\circ} \mathrm{LS}$ dan $95^{\circ} \mathrm{BT}-141^{\circ} \mathrm{BT}$, letaknya yang berada pada jalur pelayaran dunia membuat Indonesia menjadi negara yang sangat potensial dalam perkembangan dunia maritim. Untuk dapat menjadi poros maritim dunia maka banyak aspek yang harus dibenahi serta tingkatkkan, salah satunya adalah aturan regulasi untuk dunia

*) Penulis Korespondensi :

Email : dimasroman95@gmail.com kemaritiman (Perkapalan, Bangunan Lepas Pantai, dll) dalam hal ini pihak yang mengatur regulasi tersebut adalah Biro Klasifikasi Indonesia (BKI).

Peraturan BKI sendiri telah dikembangkan dari beberapa variasi yang bersumber pada regulasi nasional maupun internasional yang merupakan hasil dari studi ilmiah, penelitian dan juga praktik rekayasa keteknikan. Sekitar $90 \%$ dari peraturan regulasi untuk kapal maupun bangunan lepas pantai digunakan pada daerah yang tidak terbatas (seluruh dunia), dan peraturan ini menjamin bahwa desain struktur tersebut dapat tetap bertahan dalam keadaan pengaruh lingkungan di semua kondisi tanpa terkecuali. 
Pada rules BKI Vol II Rules for Hull - 2016 Sec.4 Design [1], disebutkan bahwa untuk menghitung $\mathrm{C}_{0} \quad$ (koefisien gelombang) menggunakan Persamaan $1-3$. Nilai 10,75 adalah nilai yang memiiliki relevansi dengan kondisi gelombang [2]. Peraturan tersebut diadopsi oleh BKI untuk peraturan Seagoing Ship berdasarkan kondisi lingkungan pada daerah Samudera Atlantik Utara (spectrum gelombang JONSWAP) [3].

$$
\begin{gathered}
C_{0}=\left[\frac{L}{25}+4,1\right] C_{R W} \\
\text { for } \mathbf{L}<90 \mathrm{~m} \\
C_{0}=\left[10,75-\left[\frac{300-L}{100}\right]^{1,5}\right] C_{R W} \\
\text { for } 90 \leq \mathbf{L} \leq 300 \mathrm{~m} \\
C_{0}=10,75 \times \mathrm{cRW} \\
\text { for } \mathbf{L}>300 \mathrm{~m}
\end{gathered}
$$

Dengan menggunakan perbedaan rata rata tinggi gelombang $(\mathrm{Hw})$ di wilayah Atlantik Utara dan Perairan Indonesia, maka kita bisa menghitung koefisien gelombang baru yang dapat digunakan untuk menghitung Design Load untuk kapal yang beroperasi hanya pada perairan Indonesia, sehingga pembuatan desain strukturnya dapat disesuaikan dan tidak terlampau berlebihan.

Beberapa penelitian mengenai analisa respon kapal telah dilakukan oleh beberapa peneliti diantaranya adalah mengenai respon struktur haluan kapal akibat beban slamming [4]. Selain itu penelitian mengenai respon struktur pondasi mesin terhadap interaksi trust block juga telah dilakukan oleh [5]. Sedangkan referensi [6] meneliti mengenai respon dari Car Deck akibat penambahan geladak / deck.

Adapun tujuan dari penelitian ini adalah untuk mengetahui perbandingan respon struktur kapal pada daerah perairan Samudera Atlantik Utara dan pada daerah perairan Indonesia. Sehingga besar reduksi total desain konstruksi kapal yang sesuai untuk kapal yang hanya beroperasi di perairan Indonesia dapat diketahui.

\section{METODE}

\subsection{Objek Penelitian}

Objek penelitian ini adalah kapal tanker kimia tipe 3 yang dikhususkan untuk mengangkut produk Kode IBC dengan bahaya lingkungan dan keselamatan yang cukup tinggi yang memerlukan tingkat penanganan sedang untuk meningkatkan kemampuan survive dalam kondisi yang ekstrim.
Kapal ini mempunyai ukuran utama (principal dimensions) sebagai berikut :

$\begin{array}{lll}\text { (Loa) } & : 99,985 & \text { meter } \\ \text { (Lpp) } & : 94,50 & \text { meter } \\ \text { (B) } & : 16,00 & \text { meter } \\ \text { (D) } & : 6,40 & \text { meter } \\ \text { (H) } & : 7,70 & \text { meter } \\ \text { Vs } & : 12,3 & \text { knots }\end{array}$

Kapal ini termasuk dalam jenis Oil Chemical Tanker yaitu sejenis kapal tanker yang berfungsi untuk mengangkut bahan kimia. Populasi kapal jenis ini bisa dikatakan jarang. Tanker ini dirancang khusus untuk mengangkut bahan kimia secara bulk. Kapal tanker tipe ini umumnya memiliki bobot mati antara 5,000 DWT sampai 40,000 DWT. Dimensi ini relatif kecil dibandingkan kapal tanker tipe lainnya. Hal ini disebabkan karena sifat yang khas dari bahan kimia dan juga karena banyaknya batasan yang diterapkan pada pelabuhan. Kapal tanker kimia biasanya dilengkapi dengan tanki khusus yang dilapisi secara khusus. Kapal jenis ini biasanya juga dilengkapi dengan sistem pemanas agar viskositas dapat dipertahankan.

\subsection{Perbandingan Perairan Atlantik Utara dan Indonesia}

Menurut data yang telah diolah dari $E C M W F$ [7] dan IACS Rec.34 - Standard Wave Data [8], tinggi gelombang rata rata $\mathrm{di}$ Indonesian Waterways dan North Atlantic Ocean dapat dibagi dalam 3 kategori, yaitu kategori T , L dan P (20, 50 dan 200 nautical miles [9].

Nilai dari tinggi gelombang rata-rata Indonesian Waterways ditunjukan oleh Gambar 1 sedangkan untuk rata-rata tinggi gelombang di North Atlantic Ocean ditunjukan oleh Gambar 2.

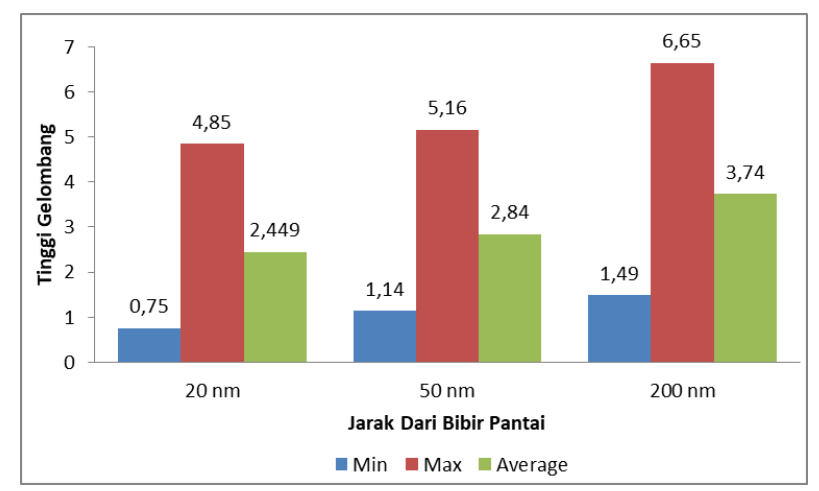

Gambar 1. Tinggi Gelombang ( $H w)$ Perairan Indonesia 


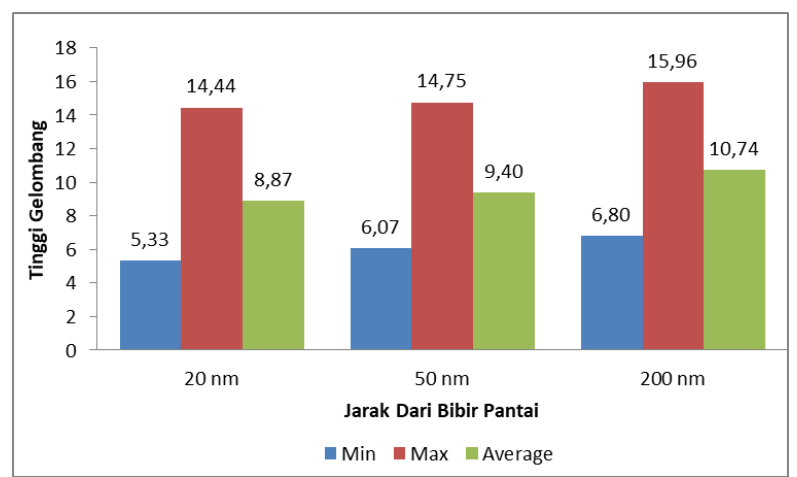

Gambar 2. Tinggi Gelombang $(H w)$ Perairan Atlantik Utara

Pada penelitian yang akan dibahas, peneliti menggunakan nilai dari rata-rata tinggi gelombang pada daerah 200 nautical miles yang mempunyai rata rata nilai $H w$ tertinggi agar nantinya desain konstruksi yang direncanakan dapat di aplikasikan ke semua wilayah pada masing masing perairan.

Untuk merepresentasikan kondisi gelombang pada lautan terbuka terdapat suatu spektrum gelombang yang dinamakan Spektrum JONSWAP. Spektrum JONSWAP secara sederhana adalah sebuah bentuk dari spectrum Bretschneider [10].

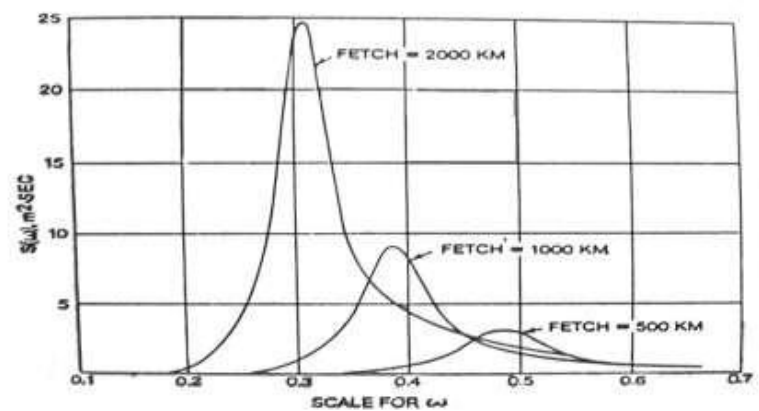

Gambar 3. Spektrum JONSWAP dalam berbagai hembusan angin (fetches)

\subsection{Permodelan dan Analisa Respon Struktur}

Tahap pendekatan permodelan merupakan pengolahan data dan pembuatan permodelan kapal, permodelan dilakukan dengan menggunakan Autocad untuk membuat lines plan kemudian dibuat model $3 \mathrm{~d}$ dengan bantuan software desain lambung kapal yang bernama Delftship.

Kemudian Maxsurf Hydromax dugunakan untuk analisa Longitudinal Strength guna mencari momen disaat air tenang, Sagging dan Hogging sesuai tinggi gelombang yang akan di analisa.

Selanjutnya untuk mendapatkan respon struktur kapal, menggunakan metode elemen hingga dengan program bantu MSC NASTRANPATRAN.

\subsection{Material Kapal}

Material yang digunakan dalam penelitian ini adalah baja Grade A dengan nilai elastic modulus $2.1 \times 10^{11} \mathrm{~N} / \mathrm{m}^{2}$, Poisson Ratio 0,3, shear modulus $8 \times 10^{11} \mathrm{~N} / \mathrm{m}^{2}$, density $7.85 \mathrm{ton} / \mathrm{m}^{3}$. Jenis elemen yang telah ditentukan kemudian diberi tebal sesuai material yang diuji. Penentuan material selesai setelah tebal material telah dimasukkan.

\subsection{Perhitungan Safety Factor}

Faktor keamanan (Safety Factor) adalah faktor yang menunjukkan tingkat kemampuan suatu bahan teknik dari beban luar, yaitu beban tekan maupun tarik. Sebelum menghitung safety factor, dicari terlebih dahulu nilai tegangan ijin yang diketahui tidak boleh melebihi dari 100/k $\left(\mathrm{N} / \mathrm{mm}^{2}\right)$ sesuai dengan ketentuan BKI Section 24 B.2.3.1

Tabel 1. Faktor Material

\begin{tabular}{cc}
\hline Minimum yield stress ReH in N/mm & $\mathrm{k}$ \\
\hline 235 & 1 \\
315 & 0,78 \\
355 & 0,72 \\
390 & 0,68 \\
\hline
\end{tabular}

Material yang digunakan pada kasus ini adalah baja Grade A yang mempunyai minimum yield (ReH) sebesar $235 \mathrm{~N} / \mathrm{mm}^{2}$. Sehingga tegangan ijin maksimum adalah $100 \mathrm{~N} / \mathrm{mm}^{2}$ atau $100 \mathrm{MPa}$. Syarat perhitungan safety factor pada pengukuran ini nilainya harus lebih dari 1 . Sebagai acuannya diambil tegangan yang paling tinggi dari tiap kondisi pembeban pada model, perhitungan Safety factor menurut tegangan ijin $\left(\sigma_{\text {ijin })}\right.$ BKI yaitu :

$$
S F=\frac{\text { Tegangan Ultimate }}{\text { Tegangan Maksimum }}
$$

\section{HASIL DAN PEMBAHASAN}

\subsection{Hasil Permodelan Kapal}

Pembuatan model menggunakan berbagai macam software, yaitu :

- Autocad

Pembuatan model di autocad adalah untuk membuat lines plan yang nantinya dipakai dalam melakukan perhitungan analisa. 


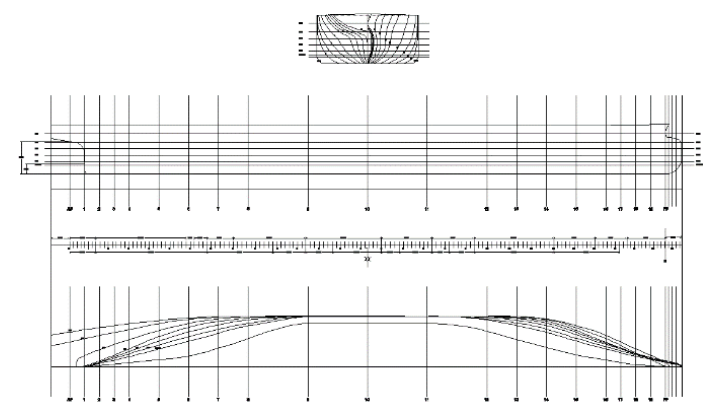

Gambar 4. Lines Plan Autucad

- $\quad$ Delftship

Pembuatan model di delftship adalah untuk mencari nilai displacement, $\mathrm{Cb}, \mathrm{Cm}$ dan sebagainya.

Design hydrostatics report.

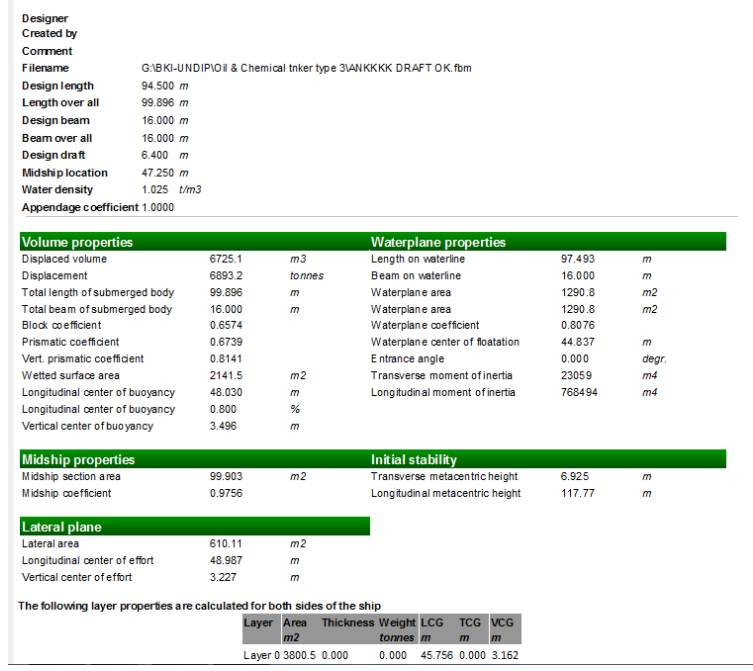

Gambar 5. Design Hydrostatic Report

\section{- $\quad$ Maxsurf}

Pembuatan model maxsurf digunakan untuk analisa kekuatan memanjang agar mendapatkan momen pada tiap daerah per airan yang diinginkan.

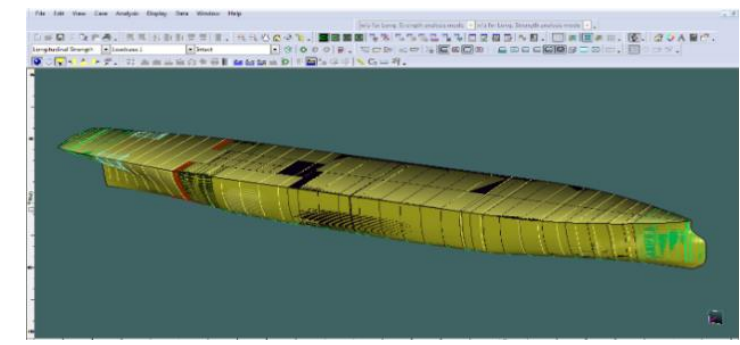

Gambar 6. Model Maxsurf

\section{- $\quad$ MSC Patran}

Untuk membuat model elemen hingga, peneliti menggunakan software MSC Patran untuk selanjutnya dilakukan analisa untuk mencari Tegangan.

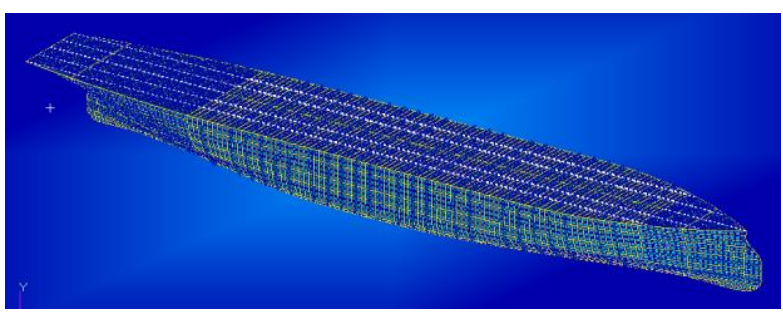

Gambar 7. Pemodelan dengan MSC Patran

\subsection{Pembebanan Struktur}

Distribusi berat ini merupakan sebagian pembebanan yang akan menimbulkan bending momen yang merupakan hasil penjumlahan dari penyebaran berat kapal kosong dengan berat muatan (DWT+LWT). Distribusi berat kapal Oil Chemical Tanker type 3 seperti pada Gambar 8.

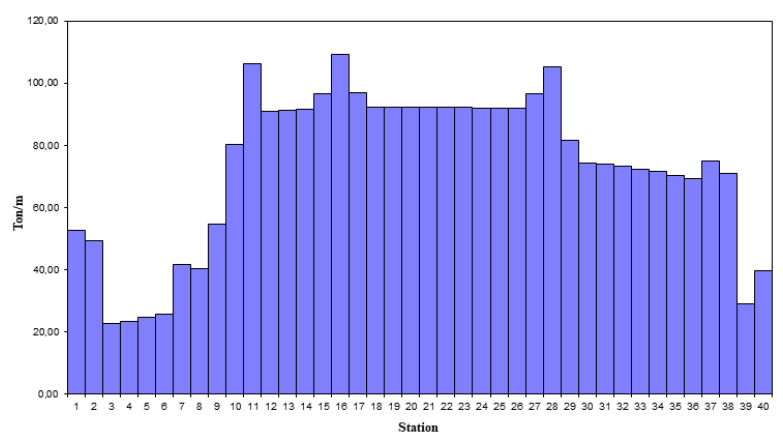

Gambar 8. Distribusi Pembebanan

\subsection{Hasil Momen Maksimum Kapal}

Diketahui momen maksimal pada saat air tenang, sagging dan hogging pada masing masing perairan yang di dapatkan dari analisa kekuatan memanjang menggunakan Maxsurf Hydromax yaitu pada Tabel 2.

Tabel 2. Momen Maksimal Kapal

\begin{tabular}{ccc}
\hline Kondisi & North Atlantic & $\begin{array}{c}\text { Indonesian } \\
\text { Waterways }\end{array}$ \\
\hline Air & 47473992,65 T.m & 47473992,65 T.m \\
Tenang & & \\
Sagging & $-59398879,05$ T.m & $-29812216,00$ T.m \\
Hogging & 147246849,75 T.m & 29812216,00 T.m \\
\hline
\end{tabular}

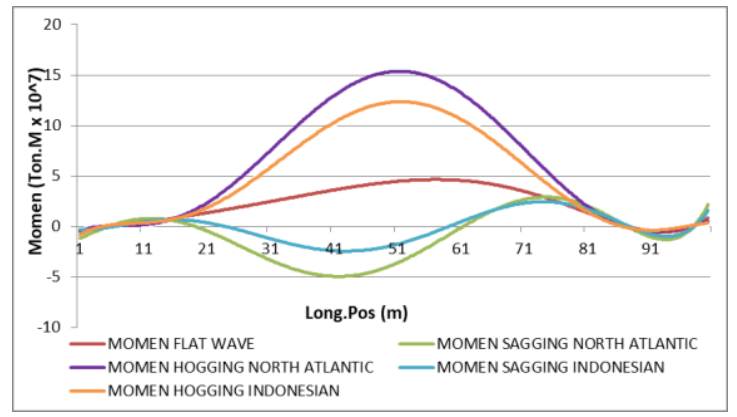

Gambar 9. Perbandingan Grafik Momen 


\subsection{Hasil Tegangan Maksimum Kapal}

Analisa menggunakan MSC Patran dilakukan dengan menggunakan pembebanan yang berbeda sesuai dengan kondisi perairan pada masing masing momen yang telah di dapatkan pada analisa kekuatan memanjang.

\subsubsection{Kondisi Air Tenang}

Hasil analisa tegangan maksimum (von misses) menggunakan MSC Patran yaitu sebesar $1,91 \times 10^{7} \mathrm{~Pa}$ atau $19,1 \mathrm{MPa}$ pada Node 68040 yang terletak pada main deck bagian tengah kapal.

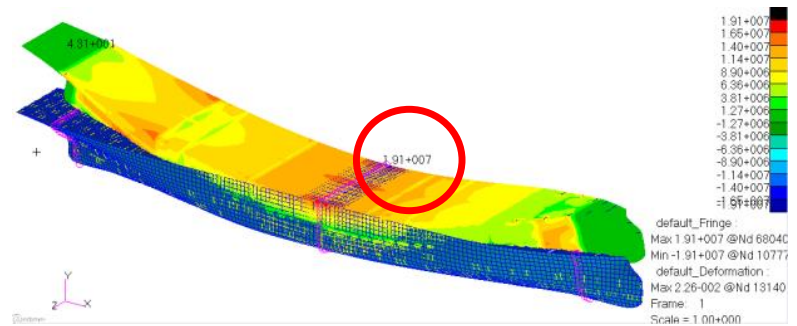

Gambar 10. Tegangan Air Tenang

\subsubsection{Perairan Atlantik Utara}

- $\quad$ Tegangan Sagging North Atlantic

Hasil analisa tegangan maksimum (von misses) menggunakan MSC Patran yaitu sebesar $2,39 \times 10^{7} \mathrm{~Pa}$ atau 23,9 Mpa pada Node 68040 yang terletak pada main deck bagian tengah kapal.

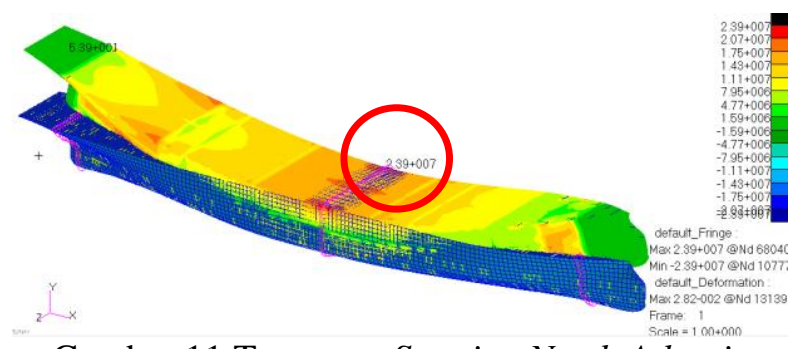

Gambar 11 Tegangan Sagging North Atlantic

\section{- $\quad$ Tegangan Hogging North Atlantic}

Hasil analisa tegangan maksimum (von misses) menggunakan MSC Patran yaitu sebesar $5,91 \times 10^{7} \mathrm{~Pa}$ atau 59,1 Mpa pada Node 68040 yang terletak pada main deck bagian tengah kapal.

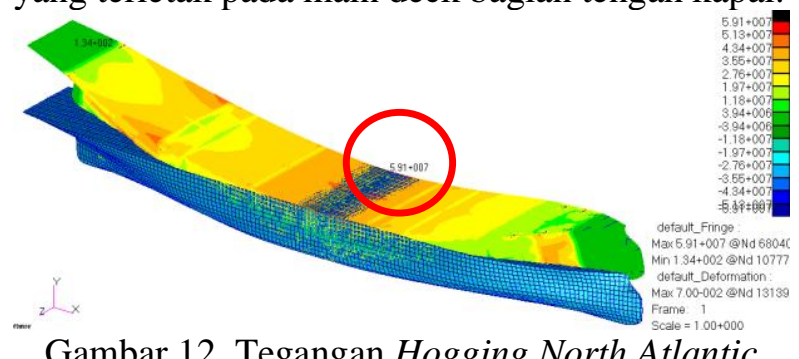

\subsubsection{Perairan Indonesia}

- $\quad$ Tegangan Sagging Indonesian Waterways

Hasil analisa tegangan maksimum (von misses) menggunakan MSC Patran yaitu sebesar $1,20 \times 10^{7} \mathrm{~Pa}$ atau $12 \mathrm{Mpa}$ pada Node 68040 yang terletak pada main deck bagian tengah kapal.

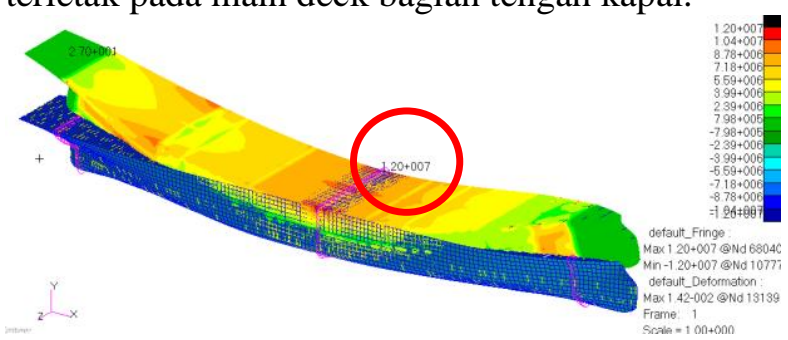

Gambar 13. Tegangan Sagging Indonesian Waterways

- $\quad$ Tegangan Hogging Indonesian Waterways

Hasil analisa tegangan maksimum (von misses) menggunakan MSC Patran yaitu sebesar $4,84 \times 10^{7} \mathrm{~Pa}$ atau 48,4 Mpa pada Node 68040 yang terletak pada main deck bagian tengah kapal.

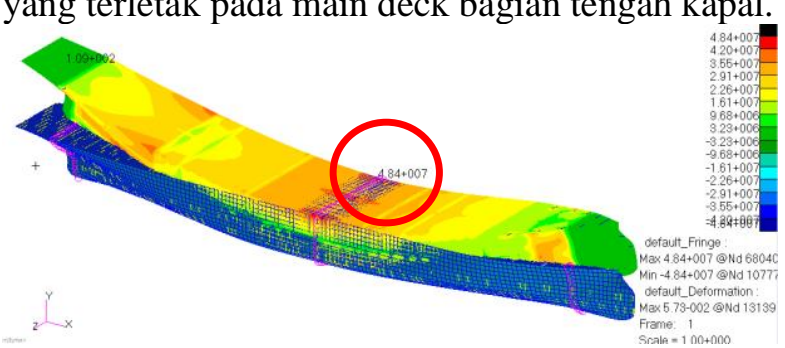

Gambar 14. Tegangan Hogging Indonesian Waterways

\subsection{Perbedaan Respon Struktur Kapal}

Dari hasil analisa yang telah dilakukan menggunakan MSC Patran, maka diketahui perbedaan respon struktur sebagai berikut :

Tabel 3. Tegangan Maksimal

\begin{tabular}{cccc}
\hline Kondisi & $\begin{array}{c}\text { North } \\
\text { Atlantic }\end{array}$ & $\begin{array}{c}\text { Indonesian } \\
\text { Waterways }\end{array}$ & $\begin{array}{c}\text { Tegangan } \\
\text { Ijin }\end{array}$ \\
\hline Air Tenang & $19,1 \mathrm{MPa}$ & $19,1 \mathrm{MPa}$ & $100 \mathrm{MPa}$ \\
Sagging & $23,9 \mathrm{Mpa}$ & $12 \mathrm{Mpa}$ & $100 \mathrm{MPa}$ \\
Hogging & $59,1 \mathrm{Mpa}$ & $48,4 \mathrm{Mpa}$ & $100 \mathrm{MPa}$ \\
\hline
\end{tabular}

Dari hasil analisa diatas, maka didapatkan perbedaan respon struktur kapal (\%) pada perairan Indonesian Waterways dan North Atlantic adalah :

Tabel 4. Perbedaan Respon Struktur Kapal

\begin{tabular}{cccc}
\hline Kondisi & $\begin{array}{c}\text { North } \\
\text { Atlantic }\end{array}$ & $\begin{array}{c}\text { Indonesian } \\
\text { Waterways }\end{array}$ & $\begin{array}{c}\text { Reduksi } \\
\%\end{array}$ \\
\hline Air Tenang & $19,1 \mathrm{MPa}$ & $19,1 \mathrm{MPa}$ & $0 \%$ \\
Sagging & $23,9 \mathrm{Mpa}$ & $12 \mathrm{Mpa}$ & $49,79 \%$ \\
Hogging & $59,1 \mathrm{Mpa}$ & $48,4 \mathrm{Mpa}$ & $18,10 \%$ \\
\hline
\end{tabular}




\subsection{Rekomendasi Desain}

Rekomendasi desain dilakukan dengan cara mencari batas maksimal dari plat yang dapat direduksi sampai tercapainya batas safety factor dari tegangan yang di dapatkan. Diketahui nilai tegangan yang terlebih dahulu mencapai batas safety factor adalah pada kondisi hogging north atlantic, dengan besar reduksi maksimal sebesar 27,33\%. Maka dari itu dapat disimpulkan bahwa untuk rekomendasi desain, nilai dari modulus profil dan tebal plat yang dapat direduksi tidak boleh lebih dari $27,33 \%$. Untuk nilai tegangan baru dari hasil analisa ditunjukan oleh Tabel 5 .

Tabel 5. Perbedaan Tegangan

\begin{tabular}{cccl}
\hline Kondisi & $\begin{array}{c}\text { Sebelum } \\
(\text { Mpa })\end{array}$ & $\begin{array}{c}\text { Sesudah } \\
(\text { Mpa })\end{array}$ & Selisih (\%) \\
\hline Air Tenang & 19,1 & 32,2 & $68,59 \%$ \\
Sagging NA & 23,9 & 40,3 & $68,62 \%$ \\
Hogging NA & 59,1 & 100 & $69,20 \%$ \\
Sagging IW & 12,0 & 20,2 & $68,33 \%$ \\
Hogging IW & 48,4 & 81,9 & $69,21 \%$ \\
\hline
\end{tabular}

Diketahui, selisih tegangan pada setiap kondisi setelah dilakukan reduksi konstruksi berkisar 69\%, namun terletak di Node yang berbeda dengan sebelum dilakukan reduksi, yaitu pada Node 10333 yang terletak pada bagian tengah main deck.

\subsection{Safety Factor}

\subsubsection{Safety Factor Sebelum Reduksi}

Tabel 6 adalah hasil perhitungan faktor keamanan (Safety Factor) sebelum reduksi. Tegangan maksimum yang dihasilkan jauh dari tegangan ijin sehingga desain konstruksi yang dibuat akan sangat berlebihan. Tentunya hal ini akan berakibat tingginya biaya material.

Tabel 6. Safety Factor Sebelum Reduksi

\begin{tabular}{ccccc}
\hline Kondisi & $\boldsymbol{\sigma}$ Max & $\boldsymbol{\sigma}$ ijin & $\boldsymbol{S F}$ & Ket \\
\hline $\begin{array}{c}\text { Air } \\
\text { Tenang }\end{array}$ & $19,1 \mathrm{Mpa}$ & $100 \mathrm{Mpa}$ & 5,24 & Aman \\
$\begin{array}{c}\text { Sagging } \\
\text { NA }\end{array}$ & $23,9 \mathrm{Mpa}$ & $100 \mathrm{Mpa}$ & 4,18 & Aman \\
$\begin{array}{c}\text { Hogging } \\
\text { NA }\end{array}$ & $59,1 \mathrm{Mpa}$ & $100 \mathrm{Mpa}$ & 1,69 & Aman \\
$\begin{array}{c}\text { Sagging } \\
\quad W\end{array}$ & $12,0 \mathrm{Mpa}$ & $100 \mathrm{Mpa}$ & 8,33 & Aman \\
$\begin{array}{c}\text { Hogging } \\
\text { IW }\end{array}$ & $48,4 \mathrm{Mpa}$ & $100 \mathrm{Mpa}$ & 2,07 & Aman \\
\hline
\end{tabular}

\subsubsection{Safety Factor Setelah Reduksi}

Pada tabel 7 disajikan data faktor keamanan Safety Factor) sesudah reduksi. Hasil menunjukan bahwa dengan pengurangan desain konstruksi hingga $27,33 \%$, nilai faktor keamanan masih melebihi 1. Hal ini akan berdampak pada pengurangann biaya material yang akan sangat menguntungkan bagi pemilik kapal. Dengan biaya material yang rendah kapal memiliki nilai faktor keamanan lebih dari 1.

Tabel 7. Safety Factor Sesudah Reduksi

\begin{tabular}{ccccc}
\hline Kondisi & $\boldsymbol{\sigma}$ Max & $\boldsymbol{\sigma}$ ijin & $\boldsymbol{S F}$ & Ket \\
\hline $\begin{array}{c}\text { Air } \\
\text { Tenang }\end{array}$ & $32,2 \mathrm{MPa}$ & $100 \mathrm{Mpa}$ & 3,10 & Aman \\
$\begin{array}{c}\text { Sagging } \\
\text { NA }\end{array}$ & $40,3 \mathrm{Mpa}$ & $100 \mathrm{Mpa}$ & 2,48 & Aman \\
$\begin{array}{c}\text { Hogging } \\
\text { NA }\end{array}$ & $100 \mathrm{Mpa}$ & $100 \mathrm{Mpa}$ & 1 & Tidak \\
$\begin{array}{c}\text { Sagging } \\
\text { IW }\end{array}$ & $20,2 \mathrm{Mpa}$ & $100 \mathrm{Mpa}$ & 4,95 & Aman \\
$\begin{array}{c}\text { Hogging } \\
\text { IW }\end{array}$ & $81,9 \mathrm{Mpa}$ & $100 \mathrm{Mpa}$ & 1,22 & Aman \\
\hline
\end{tabular}

\section{KESIMPULAN}

Hasil respon struktur kapal Oil Chemical Tanker type 3 pada daerah perairan North Atlantic Ocean pada kondisi air tenang adalah 19,1 Mpa , pada kondisi sagging 23,9 Mpa , dan pada kondisi hogging 59,1 Mpa. Hasil respon struktur kapal Oil Chemical Tanker type 3 pada daerah perairan Indonesian Waterways pada kondisi air tenang adalah 19,1 Mpa , pada kondisi sagging $12 \mathrm{Mpa}$, dan pada kondisi hogging 48,4 Mpa.

Selisih respon struktur pada kondisi gelombang air tenang, sagging dan hogging yang didapatkan melalui analisa perbandingan ini adalah $0 \%, 49,79 \%$ dan 18,10\%. Diketahui besar reduksi konstruksi maksimal yang dapat dilakukan agar tetap memenuhi nilai dari safety factor adalah tidak boleh lebih dari 27,33\% dari nilai konstruksi sebelumnya.

\section{UCAPAN TERIMA KASIH}

Penelitian ini adalah hasil kerjasama antara Departemen Teknik Perkapalan Universitas Diponegoro dan Biro Klasifikasi Indonesia (BKI).

\section{DAFTAR PUSTAKA}

[1] B.K.I, "Vol. II Rules For Hull," dalam Biro Klasifikasi Indonesia, Jakarta, 2016. 
[2] A. Kendrick dan C. Daley, "Comparative Study of Ship Structure Design Standard," Ship Structure Committee, Washington, D.C, 2007.

[3] M. A. Kurniawan, F. A. Prasetyo dan S. Komariyah, "A Comparison of Three Different Water Areas and Its Influence for Development of Rules Regulation," dalam 30 th Asian Pacific Technical Exchange and Advisory Meeting on Marine Structures, Mokpo, Rep. of Korea, 2016.

[4] T. Putranto dan A. Sulisetyono, "Analisa Numerik Gerakan Dan Kekuatan Kapal Akibat Beban Slamming Pada Kapal Perang Tipe Corvette," Kapal, vol. 12, no. 3, pp. 158-164, 2015.

[5] I. M. W. Karisma, I. P. Mulyatno dan G. Rindo, "Analisa Kekuatan Struktur Pondasi Mesin Dengan Interaksi Trust Block Pada Kapal Ferry 500 GT Dengan Metode Elemen Hingga," Jurnal Teknik Perkapalan, vol. 5, no. 1, pp. 10-19, 2017.

[6] A. Mukhsin, I. P. Mulyatno dan S. Jikosisworo, "Analisa Kekuatan Konstruksi Car Deck Akibat Penambahan Deck Pada Ruang Muat Kapal Motor Zaisan Star 411 DWT Dengan Metode Elemen Hingga," Jurnal Teknik Perkapalan, vol. 4, no. 2, pp. 341-351, 2016.

[7] "European Centre for Medium-Range Weather Forecasts (ECMWF)," Januari 2017. [Online]. Available: http://apps.ecmwf.int/datasets/data/interimfull-daily/levtype $=\mathrm{sfc} /$.

[8] I.A.C.S, IACS Recommendation No.34 Standard Wave Data, 2001.

[9] M. A. Kurniawan, F. A. Prasetyo dan S. Komariyah, "Study on wave scatter mapping of Indonesia waterways based on hindcast data," dalam 28 th Asia Pacific Technical Exchange and Advisory Meeting on Marine Structures, Istanbul, Turkey, 2014.

[10] F. B. Robert, "Volume III. Motion In Waves and Controllability," dalam Principles of Naval Architecture, The Society of Naval Architects and Marine Engineers, 1988. 